\title{
Surface Defects on Forged Nut of Stainless Steel
}

\author{
Tomonori Sasa ${ }^{1}$, Zhigang Wang ${ }^{1}$, Takashi Soga ${ }^{2}$ \\ ${ }^{1}$ Dept. of Mechanical Engineering, Gifu University, 1-1 Yanagido, Gifu, 501-1193, Japan \\ ${ }^{2}$ Ihara Science Corporation, Ihara Takanawa Building, 3-11-3 Takanawa Minato-ku, Tokyo, 108-0074 Japan
}

\begin{abstract}
Surface quality of nuts used in gas pipe joints is an important issue because the surface state affects the fatigue characteristics. Surface defects of nuts produced by warm forging from a stainless steel are observed and the cause of defect generation is discussed based on the numerical results of FEM simulation. It is revealed that there exists the lap defect on the drawn wire surface with an opened end and the surface defects on the forged nut are generated by the tensile stress during forging since there exists a moment at almost the whole area of the billet surface that a tensile stress over $200 \mathrm{MPa}$ is generated during nut forging.
\end{abstract}

\section{Introduction}

Nuts under investigation in the present paper are used in gas pipe joints (Figure 1) for experimental devices and buildings. These gas pipes serve mainly for poisonous gases and flammable gases. Serious accidents occur if the gas pipe joint in the service had been broken. Therefore the demand for nuts is severe and the surface quality of the nut is considered as an important issue because the surface state affects the fatigue characteristics $[1,2]$. However, the nuts produced by warm forging sometimes have surface defects as shown in Figure 2. The nut is produced from a drawn wire of SUS316 by four stages forging; upsetting, $1^{\text {st }}$ extrusion, $2^{\text {nd }}$ extrusion and piercing. Figure 2(d) shows a check mark on the nut surface, Figure 2(e) gives a cave-in. The cave-in appears near the bottom of the nut. A few check marks exist almost on a straight line.

These defects on nut surface perhaps become the start point of fatigue crack and cause failure finally under repeated stress [3]. Therefore the defects on the surface are regarded as a critical item and are inspected distinctly. The generation of surface defects reduces yield of material and brings cost up.

The purpose of the present work is to clarify the generation cause of surface defects on forged nuts. Surface defects are observed by SEM and then FEM simulation is carried out to discuss the stress state in warm forging.

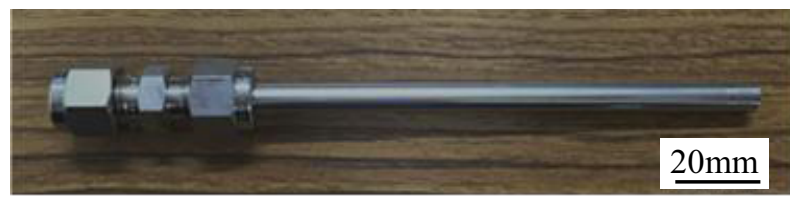

Figure 1. Nuts used in gas pipe joint.

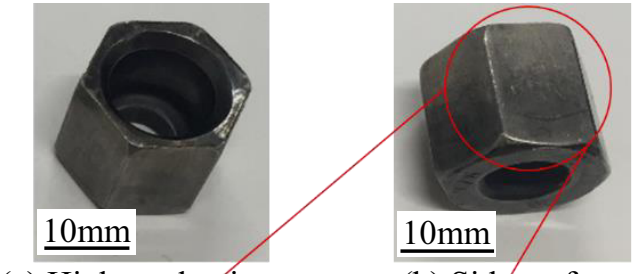

(a) High-angle view.

(b) Side surface.

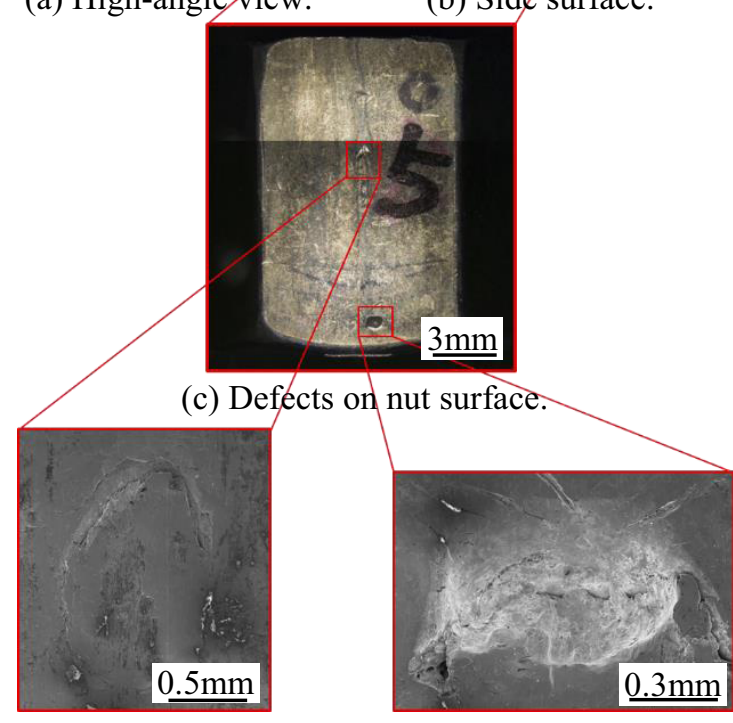

(d) Check mark.

(e) Cave-in.

Figure 2. Defects on nut surface.

\section{Observation of defects on forged nut}

First, the cause of defects on the forged nut shown in Figure 2 is considered to be peeling off of hard particles. 
As shown in Figure 3, some particulate zones are seen and their surfaces are covered by lead. As shown in Table 1, the chemical composition in the particulate zones is distinctly different with that of the stainless steel shown in Table 2. The main compositions, $\mathrm{Pb}, \mathrm{C}, \mathrm{S}$ in the particulate zones perhaps come from ingredients of the lubricant used in the forging process $[4,5]$. No hard particles can be found on the surface of forged nuts.

Table 1. Chemical compositions in particulate zone

$$
\text { (wt.\%). }
$$

\begin{tabular}{|c|c|c|c|c|c|c|c|c|}
\hline $\mathbf{K}$ & $\mathbf{C}$ & $\mathbf{O}$ & $\mathbf{S i}$ & $\mathbf{S}$ & $\mathbf{C a}$ & $\mathbf{C r}$ & $\mathbf{F e}$ & $\mathbf{P b}$ \\
\hline 0.5 & 33.4 & 7.1 & 1.4 & 7.6 & 1.1 & 2.0 & 8.1 & 38.8 \\
\hline
\end{tabular}

Table 2. Chemical compositions of stainless steel (wt. \%)

\begin{tabular}{|c|c|c|c|c|c|c|c|}
\hline $\mathbf{C}$ & $\mathbf{S i}$ & $\mathbf{M n}$ & $\mathbf{P}$ & $\mathbf{S}$ & $\mathbf{N i}$ & $\mathbf{C r}$ & Mo \\
\hline 0.04 & 0.48 & 1.6 & 0.027 & 0.02 & 10.09 & 16.56 & 2.04 \\
\hline
\end{tabular}

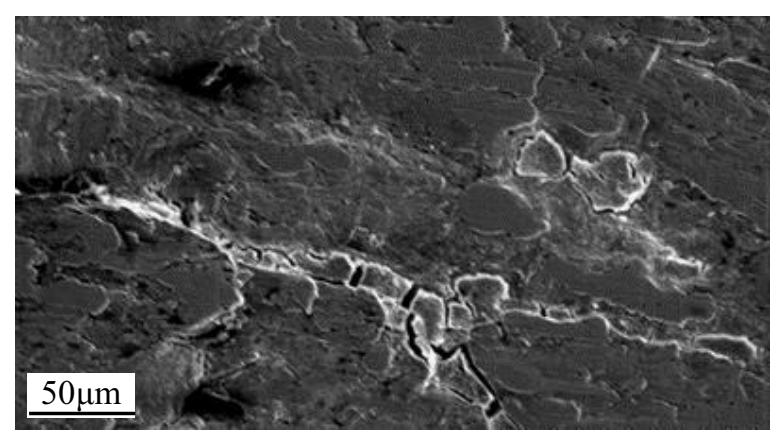

(a) Nut surface (SEM)

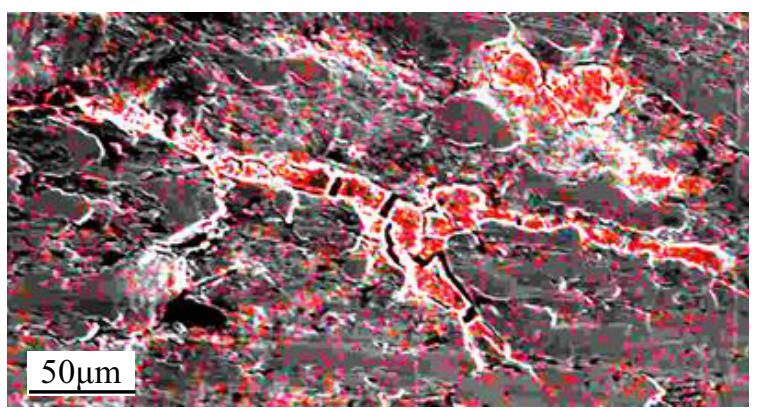

(b) Distribution state of $\mathrm{Pb}$

Figure 3. Photograph of nut surface.

\section{Observation of as-drawn wire surface}

The billet in warm forging is cut off from a coil of drawn wire. First, the billet surface is observed with a microscope. Figure 4 shows the observation results. The lap defects perhaps become the cause of the surface cracks of nuts.

The cross-sectional structure of the lap defect is observed after electrolytic etching. In electrolytic etching, the test piece with the observation plane burnished by buffing is anode; an austenitic stainless steel plate is cathode. They are connected to a power supply device and dipped into $10 \%$ oxalate solution and etched for 90 seconds under the condition of electric current $1 \mathrm{~A}$ for etching area $1 \mathrm{~cm}^{2}$. After etching, the test piece is observed by 3D laser microscope (OLS4100).

Three cross sections as shown in Figure 4 are observed. Observation procedure is shown in Figure 5. First, the billet is cut parallel with the drawing direction. 1 st cross section is observed (observation 1) after etching. Then the billet is cut vertically to the drawing direction and the 2nd and 3rd cross section are observed (observation 2, 3).

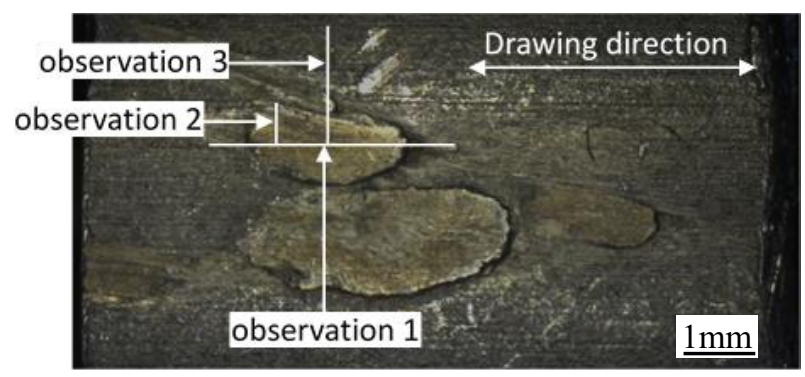

Figure 4. Defects on wire surface.

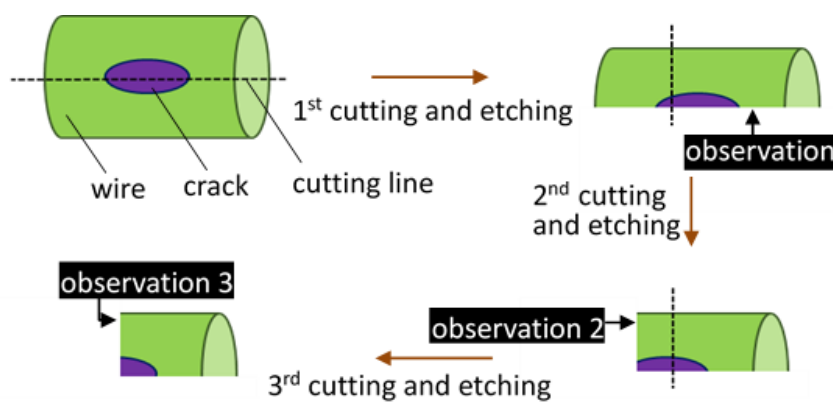

Figure 5. Process images of cross-sectional observation of defects on wire surface.

Cross-sectional structure of the defects at observation 1 is shown in Figure 6. The defect has an open end and connects perfectly at the other end. Observation 2 and 3 are made to check connecting situations in the hoop direction of billet. As shown in Figures. 7, 8, observation 2 shows almost perfect connecting although there exist caves at the ends of the defects. Observation 3 shows a crack throughout the length of the defect. It is found that the defects on the wire surface in the present study have the connecting part with the substrate material and the cracking part. It is difficult to clarify the cause of defect generation, but the possibility is extremely high that the cause of defect generation is due to unsuitable forming conditions of the rolling and wire-drawing process [6-8].

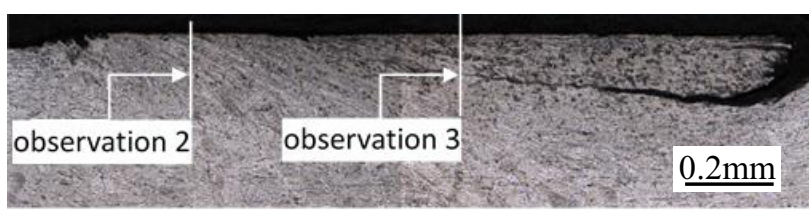

Figure 6. Surface crack at the plane of observation 1. 


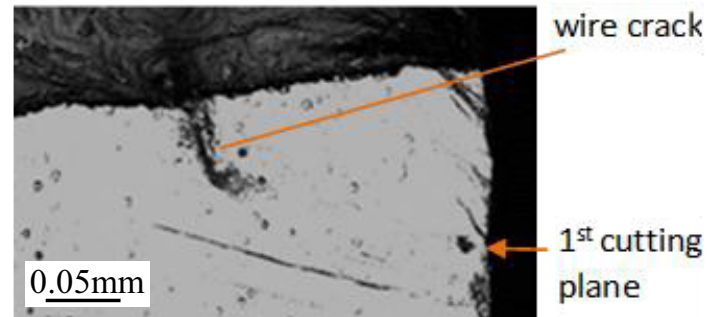

Figure 7. Crack at observation 2.

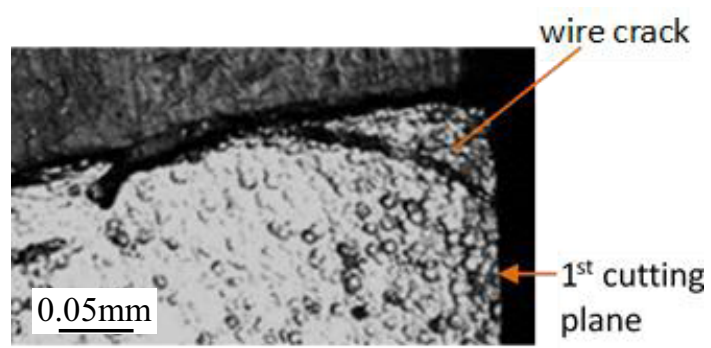

Figure 8. Crack at observation 3.

\section{FEM simulations}

FEM simulations are carried out to clarify the stress state at the billet surface in the forging process of nut. A commercial FEM code "DEFORM-3D" is used. The simulation model is shown in Figure 9. The simulation is performed by using $1 / 6$ model to reduce the time of calculation. Friction coefficient is 0.1 . The strain-stress curve of SUS316 in the software is used. The billet temperature is 300 Celsius degree that is the same as the operation in forging shop.

The nut is formed by four stages; upsetting, $1^{\text {st }}$ extrusion, $2^{\text {nd }}$ extrusion and piercing. Because the piercing process does not give any change of the nut surface, it is ignored. In upsetting, the billet is compressed by the compressing punch to close the hexagonal die and is formed to the shape of a hexagonal cylinder. $1^{\text {st }}$ extrusion is operated to make a shallow shape and then $2^{\text {nd }}$ extrusion is carried out to give a deep hexagonal hole.

Because the billet shape becomes to hexagonal at upsetting stage, the deformation state during upsetting is shown in Figure 10. The billet shape varies drastically to the hexagonal shape at the punch stroke of $3.5-5.0 \mathrm{~mm}$. The effective stain at the surface layer is about 0.6.

Figure 11 shows the stress state of the surface in the radial direction when the point 1 comes to contact with the die surface. It can be found that the surrounding area of the contact area with the die surface is in a tensile stress state.

Relation between the radial stress and punch stroke is shown in Figure 12. Horizontal axis is the punch stroke divided by the initial height of billet. A series of optional points are chosen and numbered in the order of entering contact with the die. The billet is compressed to become a shape with barrel because of friction. The die shape is hexagonal cylinder, therefore contact timing with the die
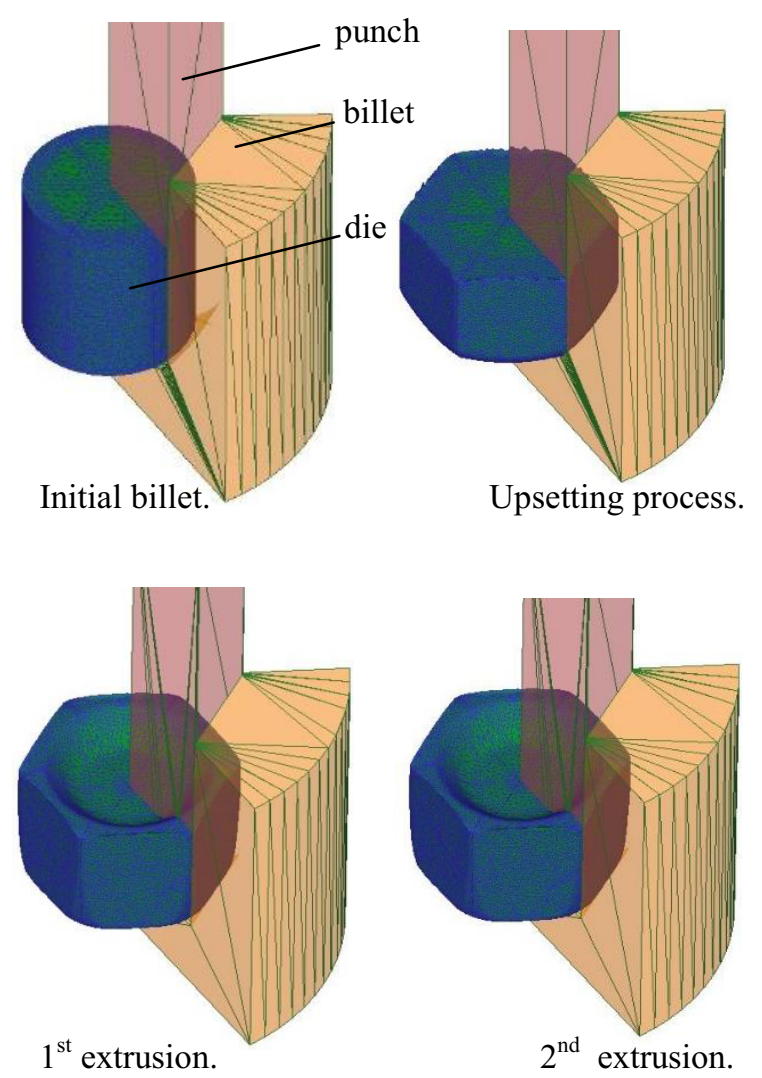

Figure 9. Forging processes of nut.

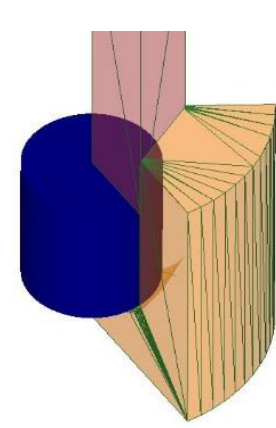

(1) Stroke $=0 \mathrm{~mm}$

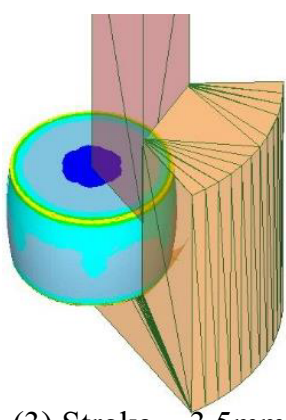

(3) Stroke $=3.5 \mathrm{~mm}$

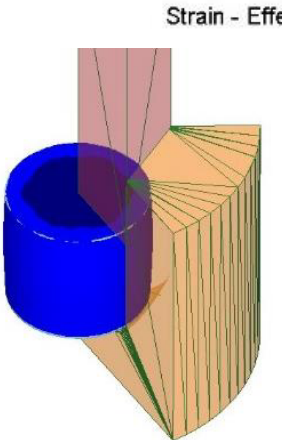

(2) Stroke $=1.5 \mathrm{~mm}$

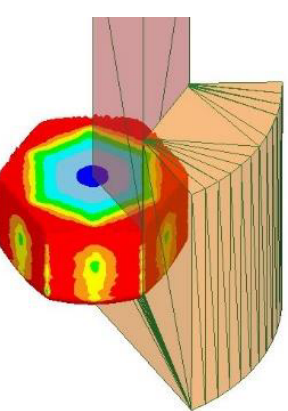

(4) Stroke $=5 \mathrm{~mm}$

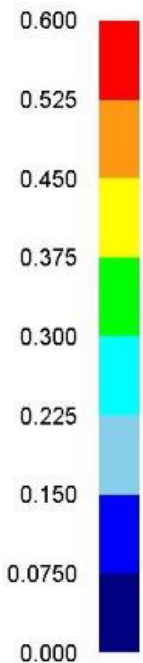

Figure 10. Change of billet shape in upsetting 
varies from point to point. When a point on the billet surface comes to contact with varies from point to point. When a point on the billet surface comes to contact with the die, a compressive stress is caused on that point, the stress value rapidly shifts to minus in Figure 12. Before the stress shifts to minus, a tensile stress near $200 \mathrm{MPa}$ is generated on the surrounding area. The tensile stress is perhaps caused by bulging as a reaction when the compressive stress is caused on the material beneath the die.

In the forging process of the nut, it is found that there exists a moment for each point on the billet surface that a tensile stress is generated. The tensile stress is larger enough to make the lap defect shown in Figure 2 separate from the billet surface and generate a cave on the forged nut surface $[9,10]$.

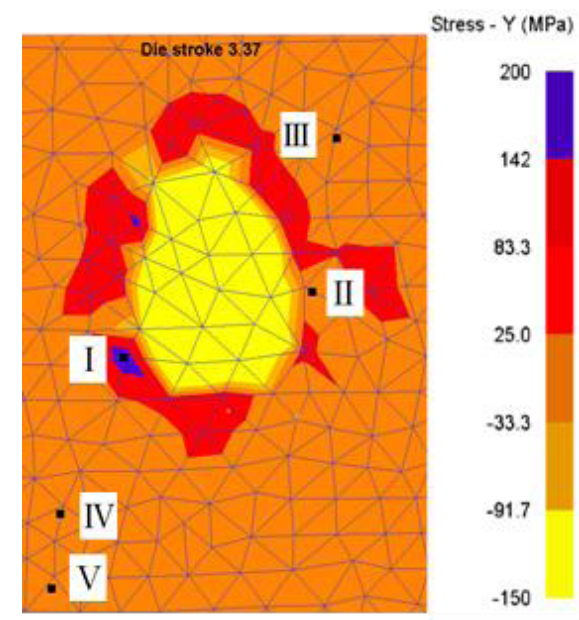

Figure 11. Image of simulation result and points position.

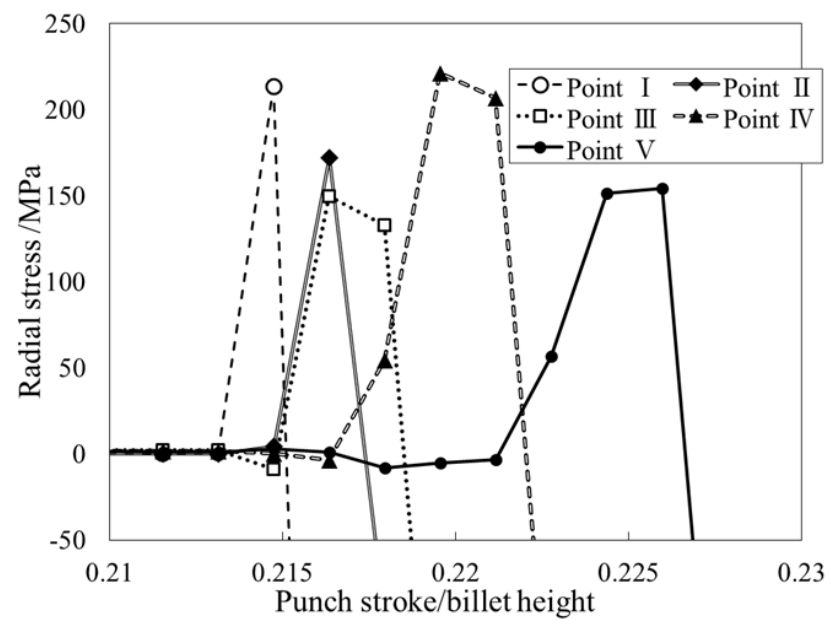

Figure 12. Relation between radial stress and punch stroke at simulated process.

\section{Conclusions}

Surface defects on the forged nut of a stainless steel are observed and the cause of defect generation is discussed based on the numerical results of FEM simulation. It is revealed that the cause of the surface defect is the lap defect with an opened end on the drawn surface and the surface defect on the forged nut are generated by the tensile stress during forging since there exists a moment at almost the whole area of billet surface that a tensile stress over $200 \mathrm{MPa}$ is generated during nut forging.

\section{References}

1. E.Sumami, Y.Sagae, Tetsu-to-Hagane, 68, 415 (1982)

2. H.Satoh, Y.Kawaguchi, M.Nakamura, M.Terashita, T.Kobayashi, Y.Isono, Wire J Int, 3, 120 (1995)

3. T.Shinohara, K.Yoshida, Tetsu-to-Hagane, 90, 1010 (2004)

4. K.Yuasa, Y.Suzuki, Tetsu-to-Hagane, 72, 1488 (1986)

5. K.Hirai, Journal of JSTP, 25, 878 (1984)

6. T.Ishikawa, N.Yukawa, Y.Yoshida, Y.Tonohara, Tetsu-to-Hagane, 89, 1142 (2003)

7. N. Yukawa, T. Ishikawa, Y. Yoshida, A. Koyachi, Tetsu-to-Hagane, 91, 861 (2005)

8. N. Yukawa, Y.Yoshida, T. Ishikawa, Tetsu-toHagane, 92,661 (2006)

9. Y. Murakami, S. Kodama, S. Komuma, Journal of JSME, Series A, 54, 688 (1988)

10. M.Kumagai, S.Takagi, F.Yakabe, Y. Jinbo, Y. Hasegawa, Surface technology, 57, 428 (2006) 